\title{
From UHSL to UHMLG: the evolution of a group for health librarians in higher education
}

\section{Abstract}

Background: In 2007 the University Health Sciences Librarians group (UHSL) merged with the University Medical Schools Librarians Group (UMSLG) to form the University Health and Medical Librarians Group (UHMLG). This paper traces the course of health librarianship in the UK which led to this event, from the perspective of the UHSL.

Methods: The narrative has been developed from the Executive Committee Minutes, Newsletters and reports of events organised by the UHSL.

Summary: The UHSL evolved from the COPOL (Council of Polytechnic Librarians) Health Sciences Group and the SCONUL (Standing Conference of National and University Librarians) Health Sciences Group. It sought to represent the views of health librarians working in the University sector. It also provided, through Newsletters and study days, information, networking opportunities and professional development. UHSL collaborated with other relevant organisations to further its aims.

Conclusion: The structure of professional support groups within health librarianship reflects the evolving nature of the health service, higher education and the social changes driven by technological developments.

Keywords: Health Librarianship, History of Librarianship, University Health Sciences Librarians (UHSL),

\section{Introduction}

If the University Health and Medical Librarians Group (UHMLG) has a birthday it probably is the $12^{\text {th }}$ July 2007 when the Annual General Meeting of the University Medical Schools Librarians Group (UMSLG) voted to amalgamate with the University Health Sciences Librarians Group (UHSL). This 
development was the result of several years of formal and informal discussion between the Executive Committees of the two groups and many more years of active co-operation between them. It reflected, as did the original creation of the two groups themselves, the changing worlds of health care and higher education within which professional health care librarians operate.

The focus of this article will be on the activities of the UHSL and its evolution into the UHMLG. The history of the UMSLG has been discussed elsewhere ${ }^{1}$.

\section{COPOL Health Sciences Group}

UHSL came into being in 1994. Its origins can be traced back to the COPOL Health Sciences Group. This group originally seems to have been a subject based self-help group which held its initial meeting at the North London Polytechnic in December 1985. (Details of the group's Study Days can be found in the Appendix). In this sense it was created out of informal meetings of librarians with shared needs and interests, as was the case with UMSLG and the NHS Regional Librarians Group (NHS RLG) ${ }^{2}$. According to Palmer the COPOL group "suspended its activities .... in response to a feeling of health service librarians in the old polytechnic sector that they did not have an appropriate forum where issues/developments that concerned them could be addressed" 3 .

One of the prime motivators in bringing the members of UHSL together was the change in nurse education that took place in the early 1990's. The Project 2000 proposals brought nurse education into the higher education sector ${ }^{4}$. The aim was to encourage students to become more self sufficient in their learning and to make them more aware of the research basis of their practice. Trained nurses were also to be expected to "demonstrate that they have maintained and developed their professional knowledge and competence" after initial registration ${ }^{5}$. These developments resulted in all Schools and Colleges of Nursing being integrated into higher education by the mid-1990s. 
The management structures of the amalgamations were many and varied, as were the arrangements for library services which accompanied them. In some areas nurse education was fully integrated into University structures along with their libraries. In others the old Schools and libraries may have been integrated in name only. Sometimes medical libraries would take on responsibility for providing services for nurses and other health professionals.

For many universities nurses and allied health professionals were a new breed. They arrived in large numbers at several times of the year and they were being professionally exhorted to base their practice on research resources. The many changes prompted responses from librarians. There were concerns about standards and the need to monitor library provision, about adequate levels of funding and about cooperation between the service providers. There was also a need to respond to new educative approaches. Knowing how to find research based information implies knowing how to understand and assess what has been found. Librarians found themselves needing to aid students working within enquiry- or problem-based learning frameworks. Information itself moved from being largely print based to being networked and electronic. Whether working with students or providing information to clinicians library staff needed to become skilled in methods of resource discovery and critical appraisal.

\section{The Cumberlege Seminars}

The higher education library community began to respond to these changes. Following representations from SCONUL's Advisory Committee on Medical Materials (ACMM), which included UMSLG members, the British Library (BL) identified the need for a review of medical information needs. In July 1992 a seminar, chaired by Baroness Cumberlege, was arranged by the BL's Medical 
Information Review Panel to raise the profile of Library services within the NHS and the Department of Health. In December 1992 a Cumberlege Organising Committee (COC) was formed. NHS RLG and UMSLG were represented on the committee and a second seminar chaired by Baroness Cumberlege was held in October 1993.

After an organisational review SCONUL set up an Advisory Committee on Health Services (ACHS) in November 1993 as a successor to its ACMM. Also at this time the Library and Information Co-operation Council (LINC), a multi-sectoral committee with links directly to government, was considering organising a "Health Panel" and invited the COC to make recommendations. It was suggested that setting up a health panel would help the sector to 'speak with one voice'.

At what might be considered a less formal level there was a sense that health and social care librarians within the polytechnic sector were unrepresented. The UMSLG, representing only Medical Schools at this time, was considered exclusive, while the constituency of Libraries for Nursing (LfN), a sub-group within the Library Association, was narrowly concerned with NHS libraries and services for nurses. In 1992 and 1993 the COPOL Health Sciences Group held a series of Study Days to raise awareness of the upheaval which many university and nursing libraries were going through as a result of the move of nurses into higher education ${ }^{6,7}$

\section{The SCONUL Health Sciences Group}

When the polytechnics were reconstituted as universities in 1994 the COPOL Health Sciences Group became the SCONUL Health Sciences Group. According to its promotional literature the SCONUL HSG sought to act as a forum for the interchange of ideas and to contribute towards the discussion of issues relating to the health sciences in higher education (HE) libraries. Membership was open to health sciences librarians in HE. 
The main activities of the group were to include organising regular study days, providing responses at national level to matters of concern to members, disseminating information on health science librarianship to members and liaising with groups with complementary interests (e.g. UMSLG, NHS RLG, and other NHS employee and Library Association (LA) groups). The Group also felt it worth stating that it planned "to exploit the electronic transmission of information as well as traditional methods in communicating with its members"

In recognition of their overlapping constituencies a joint LfN / SCONUL HSG study day was held on $12^{\text {th }}$ May 1994: Nurse Education and Higher Education: tendering and contracting at the Royal College of Physicians ${ }^{9}$.

A Joint Forum of the HSG, NHS RLG and UMSLG was held on $8^{\text {th }}$ June 1994. This was probably the first of what were known as the Tripartite meetings. These meetings gave committee members of the Medical School Librarians, the university based health science librarians and the senior NHS librarians the opportunity to meet and exchange views. Chairmanship of the meetings rotated around the groups. Items discussed at this first meeting included plans for the LA to set up a 'Task Force' on health information and the possibilities of a LINC Health Panel.

\section{The University Health Sciences Librarians Group (UHSL)}

SCONUL decided that to continue to support the the Health Sciences Group would conflict with the work of the ACHS. The HSG therefore had to establish an independent existence. A draft Constitution for the new group was presented at the May Study Day and an amended version was agreed at the HSG study day held at De Montfort University in November 1994. The proposed name for the group was to be the Health Sciences Librarians Group in the University Sector. It was agreed that University Health Sciences 
Librarians Group, usually known as UHSL, provided a slightly more memorable name. A Steering Group would be established from volunteers and elections for an Executive would be held in 1995. Members of the initial Steering Group and the first Executive Committee were Graham Walton (Chair). Jill Beard (Secretary), Dave Hiscock (Publicity), Liz Fairclough (Study Day Organiser) and Maurice Wakeham (Treasurer). Wendy Bastable and Barbara Hull were also committee members ${ }^{10}$.

At the November 1994 Tripartite a meeting at the Library Association regarding health care information was discussed, along with the impact of merging NHS Colleges into HE, and the proposed LINC Health Panel. UHSL Executive members' attendance at these meetings tended to take the form of a pre-meeting discussion in a local pub before the gruelling business of committee work!

UMSLG and UHSL representatives had a meeting (9.11.94) with the English National Board (ENB) who were responsible for supervising nursing and midwifery education. A national formula for education costs was required and it was decided that SCONUL-ACHS should lead on this.

One of the main issues at this time involved access to resources by trained nursing staff, where universities had taken over Nursing School Libraries. Other issues of concern included the role and funding of management libraries in the NHS, services to the allied health professions, health information sources, and the accreditation of health libraries.

\section{Formation of the LINC Health Panel}

Formal Consultation for a LINC Health Panel (LINC HP) was issued in February 1995. UHSL responded to this positively and was invited to participate in an interim Panel, which was launched on July $17^{\text {th }} 1995$. UHSL was represented by Jill Beard on the Executive Committee. She was also the Panel's Honorary Treasurer. UHSL became a Foundation member which entitled it to representation on the LINC HP Executive. 
The first AGM of the LINC HP was held in February 1996. The first Executive Meeting of the Panel set up a project to investigate Library and Information Services to the nursing profession. UHSL contributed funding to support this three UHSL committee members were on the Steering group. The RLG Accreditation Working Party would work under the auspices of the Panel and would go on to produce an Accreditation manual for consultation at the Exeter Health Libraries Group Conference in September 1996. A brief scoping study for a National Health Information Plan was also endorsed at this first LINC HP AGM.

\section{The work of the UHSL: Newsletters and Study Days}

UHSL produced its first Newsletter in July1996. Among other things this reported on the major seminar on integrating nurse education into the higher education sector held in Newport in June $1996^{11}$. UHSL was one of the organising bodies of this meeting and members of the Executive made presentations. The Newsletter was distributed in paper format and on lismedical, a discussion list owned by UMSLG, which was an early example of UMSLG / UHSL collaboration. The setting up of UHSL web pages was also set in train. A closed discussion list was established for the UHSL Executive Committee.

UHSL had a promotional stand at the Exeter HLG conference and enrolled 24 additional members. Unlike UMSLG, whose membership was institutionally and subscription based, UHSL allowed individual memberships, open to 'health science librarians with an interest in higher education' and funded its activities through profits made from study day activities. One of the issues for UHSL throughout its life would be the involvement of the membership and getting people to work on the Committee. The January1997 Study Day on Information Skills in the electronic age also served as the AGM. Jill Beard remained Chair for 1997. Jean Yeoh (St Georges), Jan Nicholls (University of the West of England) and Sean Farrely (Thames Valley) agreed to be coopted for 1997. 
At the February 1997 Tripartite meeting it was decided that the Secretaries of the three groups should circulate their respective Minutes to one another, which the Minutes of the January 1998 Tripartite meeting indicated did take place.

The second UHSL Newsletter appeared in March 1997 with reports on the Executive, Study Day, plans for future study days including a joint UMSLG / UHSL event, suggested web pages, OMNI (a medical subject gateway), LINC HP, Tripartite meeting, and the $5^{\text {th }}$ European Association for Health Information and Libraries (EAHIL) Conference.

In June 1997 the LINC Health Panel published its report, Library and Information Services for the Nursing Profession: Methods of Funding and Delivery, which had been carried out by Sue Capel at the University of Northumbria's Department of Information and Library Management. (The report would be extended in 1998 to include the professions allied to medicine). The LINC HP worked with SCONUL in relation to establishing a protocol for Library and Information Services for Health Professionals. In 1999 this became the Panel's Partnership Working Group.

The Health Panel also had a subgroup which was producing a document and process for library accreditation. This proved to be a marketable and profitable document when published in 1998 and was approved by the ENB and the Scottish National Board.

In June 1997 Jill stood down as Chair of UHSL and Honorary Treasurer of the LINC Health Panel due to pressure of work. Liz Fairclough took over as UHSL Chair. She wrote in an email to the Committee "we've been pretty successful with study days and making ourselves a voice in the challenging world of health libraries, and our membership reflects this" (email 1.7.97). A possible joint study day with UMSLG on the strategic implications for libraries of the Dearing report, the recently published report of the National Committee of Inquiry into Higher Education, was discussed at the July UHSL executive 
committee meeting. Another subject for discussion between the two groups was the 1997 Department of Health Circular on Library and Information Services (HSG 97(47)). This Health Service Guideline was officially launched in November 1997 at a seminar entitled Operating with Knowledge organised by the Health Libraries Group.

A UHSL study day jointly organised with LfN ran at Newcastle in November 1997. It was entitled Informed health library services: using research to shape our practice. Presentations at this event were concerned with the recent Library and Information Commission Research Strategy, using evidence as a basis for library services, the IMPEL 2 project on the impact of e-resources and the LINC HP's research on services for nurses. This meeting also saw the launch of a UHSL web site, based at South Bank University. This would soon feature reports and photos of study days, copies of the group Newsletter and links to relevant web sites ${ }^{12,13}$. UHSL was also working with Health Libraries Review (HLR) to promote a 'New writing in health sciences' award for an article by an unpublished author on a health library related topic. Only one entry was received by the March 1999 closing date so it was decided not to make an Award. However the entry was published as a Brief communication in the $\mathrm{HLR}^{14}$..

The third UHSL Newsletter, produced, like previous issues by Roisin Gwyer, appeared in March 1998. It updated readers on several health library related study events, useful web sites, news of LINC HP activities and the UHSL's own plans. Other issues being discussed at this time were the need for improved interconnectivity between the NHS and HE, plans for a National Electronic Library for Health (NeLH) and proposals for a National Centre for Clinical Excellence.

\section{UHSL and research}

UHSL was represented on the LINC HP's Research Working Party, which was created out of the former HLG/UMSLG Research group in April $1999^{15}$. The group would advise and support the LINC Health Panel on research 
related issues. It would seek to identify new and ongoing research. The Working Party also liaised with the Library and Information Research Group (LIRG) about introducing a health information thread to a successful research methods course which LIRG was running at the time. The group was also responsible for launching a Research in the Workplace award, to be funded by the constituent groups, including UHSL. It also sought to promote the concept of evidence based librarianship.

By 2000 UHSL began to suffer from problems that sometimes beset voluntary groups.

How to encourage people to become actively involved in UHSL was a frequent cause for discussion at Executive meetings and became more difficult if regular events where members could meet were not held. Committee members left the health sector or the profession or found themselves with increased responsibilities elsewhere. Since many 'members' of the group did not formally join but just attended meetings, it proved difficult to maintain a membership list. Such factors meant that UHSL failed to hold a study day in the autumn of 1999 and the newsletter ceased production in 2000. In January 2001 the Executive decided to put more effort into developing a web presence. The group obtained its own domain name. A revamped UHSL web site was launched. The site, mainly produced by Matthew Lawson (South Bank University), would eventually include details of the Executive committee, membership application forms, and links to study day presentations, related professional groups, relevant official publications and UHSL produced reports. The web address was www.uhsl.ac.uk, which, at the time of writing, is no longer accessible.

At the January 2001 Executive meeting discussions took place on a possible research project relating to HE concerns in working with the health service. By the end of the year UHSL had commissioned a project entitled 'Making a difference: effects of the Government's nursing, midwifery and health visiting strategy on LIS services in the health sector'. The issues investigated included access to IT, coping strategies for increasing student numbers, involvement with new pedagogic approaches such as problem-based learning 
and support for students on placements. The report was published in January 2002 and also made available online via the UHSL website. It was also written up in the academic press ${ }^{16}$. The Group continued to support the Research in the workplace award throughout its life.

\section{Health library groups restructure}

At around this time the LINC was wound up. The Health Panel sought to join with Re:source (the Museums, Libraries and Archives Council, successor organisation to the Library and Information Commission and the Museums and Galleries Commission) or the Library Association but in fact remained independent of both organisations. It was later renamed Helicon (Health Library and Information Confederation). UHSL was involved in the review of the roles of SCONUL-ACHS and the LINC HP, and with HE-NHS relationships in London via the M25 group. UHSL Executive members also began to discuss closer links with UMSLG colleagues as the interests of the two groups continued to converge. Several meetings took place to discuss the roles of the various Health LIS groups and their interrelationships (UMSLG Minutes 22.7.01).

In the autumn of 2001, a tripartite meeting took place in the context of further health service reorganisation. Workforce Development Confederations were taking on broader educational roles, Strategic Health Authorities were being reduced in number and Regional Offices being slimmed down. The meeting specifically discussed future UMSLG/UHSL relations. This would be the last of these meetings as the RLG decided to withdraw their support, feeling that the meetings no longer served a purpose. They proposed that the three groups use the SCONUL ACHS or Helicon committee as a forum for meeting and exchanging information.

In November 2001 an NHS-HE Forum met to look mainly at the barriers to cross sector working, such as computer networking, funding and content licensing issues. The group would report to the NHS National Information Policy Board and the Joint Information Systems Committee (JISC). An NHS 
University was also being planned at this time though this would prove to be a dead end. NeLH and NHS Direct also provided information services which overlapped with HE provision.. The Forum set up a Content group, in which UHSL was invited to participate ${ }^{17}$.

Under the auspices of SCONUL ACHS Chairs of the key health information groups met in June 2001. Common themes identified were advocacy, influencing policy makers and partnerships. The SCONUL group found it was doing similar things to Helicon and RLG. SCONUL revised its terms of reference (March 2002) to include "To encourage, support and facilitate regional and national partnerships with the University Medical School Librarians and University Health Sciences Group and other Groups as appropriate" perhaps indicating a realisation of the need to consult and communicate more widely. In November 2002 in response to the organisation of the NHS into a collection of Workforce Development Confederations, the RLG agreed to transfer its work into the NHS Library and Knowledge Development Network which had its first meeting in February 2003.

UHSL was represented at a meeting between the Helicon Executive and Re:source about the relationship between the health sector and other library sectors in January 2003. The Chairs of UHSL and SCONUL ACHS met in March 2003 to discuss relationships between their respective groups. By the end of the year SCONUL had decided to wind up the ACHS and replaced it with a SCONUL Health Strategy Group which would consider health issues at a strategic level, liaising with the NHS, Department of Health and the JISC. The SCONUL Group was concerned about duplicating the effort of the NHSHE Forum and was also interested in issues of information literacy and research. Margaret Haines became Chair of the new group and UHSL representatives discussed with her and UMLSG possible futures for the various Groups. Also around this time the Information Focus for Allied Health sub-group (INFaH) of the cilip Health Libraries Group ceased operating and merged with LfN.

\section{Towards integration}


UMSLG was also concerned about its future at this time. Tom Roper wrote about the Group's discussions in his blog:

Next came the AGM, where we ... discussed the future of the organisation, our relationship with UHSL and with SCONUL. I shan't usurp the function of the minute taker, but will simply throw in my view, which is that now is the time to build a new, unified and broad-based organisation [for] health librarians in higher education, drawing on the best traditions of predecessors... But it was apparent in discussions ... that it makes sound sense for us to combine with colleagues to provide one voice for higher education librarians serving health ${ }^{18}$.

The UHSL Executive Committee, now chaired by lain Baird (University of Teeside) after Liz Fairclough left the HE sector, continued to meet regularly over the next few years. In May 2004 members met with their UMSLG opposite numbers to discuss issues affecting library support for health in HEls and the pros and cons of a merger of the groups. Unlike UHSL UMSLG did maintain a programme of events while continuing to debate its future role ${ }^{19}$. UHSL also produced a discussion document ${ }^{20}$, while UMSLG discussed amalgamation at its 2006 AGM. .

Following consultations within the Groups and discussions between the Executive Committees, particularly Linda Dorrington, Chris Fowler and Betsy Anagnostelis for UMSLG and lain Baird, Roisin Gwyer, Maurice Wakeham and Angela Horrocks for UHSL, terms of reference and a Constitution for a possible new group were drafted. In May 2007 a Joint UMSLG / UHSL Forum on e-learning was held and at which the results of the Committees' deliberations were announced to members ${ }^{21}$. The University Health and Medical Librarians Group came into being on $1^{\text {st }}$ August after being approved at the UMSLG AGM in July 2007. 


\section{Conclusions}

UHSL came into being as a result of changes in approaches to nurse education and the responses required by academic librarians in dealing with those changes. The issues being faced included funding, NHS/HE relations, numbers of students, multidisciplinary working, evidence based practice, problem based learning, services for students on placement and quality of service. The existing professional organisations were perceived to be unresponsive to the needs of HE health librarians. UHSL sought to be both inclusive and flexible. Throughout its life the group held study days, several of which were held collaboratively with other organisations. The meetings were well supported, held across the country and included presentations from nationally respected researchers, academics and practitioners.

UHSL worked to represent its constituency within national organisations such as SCONUL and Helicon. In practice these were competing with one another to speak for health librarianship 'with one voice' but suffered from conflicting objectives and overlapping memberships. Many rank and file librarians, while supportive of group activities, were reluctant to participate in organising them. By the late nineties they were more able to find professional support through development of a range of virtual forums.

Like UHSL, the UMSLG were also going through a series of internal discussions and debates about that group's 'fitness for purpose'. The result of these discussions within and between the groups was the merger to form the UHMLG in 2007, which was but one of several changes within the structure of professional health librarianship support in the early years of the twenty first century. At the end of 2007 the group is actively seeking relevant and exciting ways by which it can involve, develop and support its membership.

\section{Appendix}




\section{University Health Sciences Librarians Group Study Days}

December 1985 COPOL Health Science Subject Librarians Meeting Polytechnic of North London

June 1992 COPOL Health Sciences Study Day

Developments in nurse education and their library implications

Royal College of Nursing

May 1993 COPOL Health Sciences Study Day

Liaison with academic staff

Royal College of Physicians ${ }^{6}$

November 1993 SCONUL Health Sciences Group Study Day

Mergers between NHS Colleges and Higher Education: Library implications and issues

University of Central England ${ }^{7}$

May 1994 SCONUL Health Sciences Group Study Day

Nurse education and higher education: tendering between institutions

Royal College of Physicians ${ }^{9}$

November 1994 Health Sciences Group Study Day

Supporting research in the health sciences

De Montfort University, Leicester ${ }^{10}$

May 1995 UHSL Study Day

Accreditation - practical action

University of North London ${ }^{22,23 .}$

November 1995 UHSL Study Day

Evidence based health care: an introduction for health librarians 
University of Portsmouth ${ }^{24}$

June 1996 SCONUL ACHS / UHSL / NHS RLG / UMSLG Seminar

Integrating nurse education into the higher education sector

University of Wales College of Medicine ${ }^{11}$.

January 1997 UHSL Study Day

Information skills teaching in the electronic age

Thames Valley University

November 1997 Joint LfN / UHSL Study day

Informed Health Library Services: Using research to shape our practice..

University of Northumbria, Newcastle ${ }^{12,13}$

December 1998 UHSL Study Day

Keeping students at a distance: supporting distance learners.

University of the West of England, Bristol

July 1999 UHSL Study Day

How to score in the library: QAA for nurses, midwives and PAMs

Sheffield Hallam University

May 2000 Joint UHSL/LfN Study Day

Raising your e-levels: electronic advances in health information.

University of Derby

December 2000 Joint UHSL / LfN Study Day

Making connections: partnerships and recent government initiatives

St Pancras Conference Centre, London ${ }^{25}$

May 2001 UHSL Study Day 
Making a difference: the changing role of librarians in learning and teaching. University of Coventry

May 2002 UHSL Study Day

Making a difference - Meeting the challenge: Higher education working with confederations for the education and training of health professionals

Department of Health, London.

May 2007 UMSLG / UHSL Open Forum

e-learning in health and medicine

Woburn House, London ${ }^{21}$ 


\section{References}

1. Morgan, P. A history of the University Medical School Librarians Group. Bishop and LeFanu Memorial Lecture. 2000, Available at: http://www.umslg.ac.uk/history.htm [Accessed 23/07/2007]

2. Forrest, M, and Carmel, M. The NHS Regional Librarians Group. Health Libraries Review 1987, 4(3) 160-163

3. Palmer, J. Professional associations in health information. Medical Health \& Welfare Libraries Group Newsletter 1994, 11(1), vii-xiii

4. UKCC Project 2000: a New Preparation for Practice. 1986, London: UKCC.

5. UKCC Report of the Post Registration Education and Practice Project (PREP) 1990. London: UKCC

6. Wakeham, M. Liaison with academic staff. Report of a study day of the COPOL Health Sciences Group at the Royal College of Physicians. 13 May 1993. Health Libraries Journal 1993, 10(3), 145-146

7. Stewart, D. Mergers between NHS Colleges and higher education: library implications and issues. COPOL (Health Sciences) study day. Health Libraries Review 1994,11(2), 144-146

8. SCONUL Health Sciences Group flyer, n.d.

9. Libraries for Nursing. Nurse education and higher education: tendering and contracting between institutions Libraries for Nursing Bulletin 1994, 14(2), 11 18 
10. Walton, G Supporting research in the health sciences: study day organized by the University Health Sciences Librarians Group Health Libraries Review 1995, 12(2), 133-134

11. SCONUL Integrating nurse education into the higher education sector: a seminar on the challenges facing librarians 1996, LISCW.

12. Aiton, A. Informed health library services: using research to shape our services UHSL /LfN study day Interim (SHINe Journal) 35 Winter 1997 / Spring 1998, 9-11

13. Wakeham, M. Informed health library services: using research to shape our practice. Joint LfN/UHSL study day. Health Libraries Review 1998, 15(2), $136-138$

14. Blenkinsopp, J. Reflections on evidence-based practice training. Health Libraries Review 1999, 16 (4), 274-277

15. Wakeham, M. The LINC Health Panel Research Working Party. Libraries for Nursing Bulletin 1999, 19(2), 14

16. Gannon-Leary, P Wakeham, M \& Walton, G. 'Making a Difference' to nurse education: the impact on HE libraries. Journal of Librarianship and Information Science 2003, 35(1), 31-46

17. Ayris, P. \& Teague, M. The NHS-HE Forum. Library and Information Research 2006, 30(94), 10-16

18. Roper, T. Tom Roper's blog. 2004,. Available at http://tomroper.typepad.com/tr/2004/07/umslg_2004.html [accessed 27.7.2007] 
19. Fowler, C. Discussion paper: the future direction of UMSLG. A debate for members. UMSLG web page. 2005, Available at

http://www.umslg.ac.uk/discussion_paper.htm [Accessed 10/08/2007].

20. UHSL $A$ single group for University Health and Medical librarians in Higher Education? A discussion paper. n.d.

21. Wakeham, M. e-learning in health and medicine. UMSLG / UHSL Open Forum. Health Libraries Group Newsletter. 2007, 24(2), 30-32

22. Beard, J \& Wakeham, M. Accreditation - practical action. Report of the UHSL study day. SCONUL Newsletter 1995, 5/6, 9-10

23. Wakeham, M. University Health Science Librarians study day: accreditation - practical action. Health Libraries Review 1995, 12(4), 310-311 24. Farrelly, S. Evidence based Health Care - an introduction for librarians. UHSL Study day. SCONUL Newsletter 1995, 5/6, 10-12

25. Shelley, J.. Making connections: partnerships and recent government initiatives. Libraries for Nursing 2001, 21(1), 10-14 


\section{Implications for Policy}

- Professional support groups such as UHMLG have a role to play in enabling information workers to respond to change across institutional, geographical and sector boundaries.

- NHS and HE managements should encourage and work with such groups in order to improve communication and library and information services to the health sector.

\section{Implications for Practice}

- Professional groups like UHSL and UHMLG often develop out of informal discussions in response to perceived failures of existing structures to represent coherent groups within the profession.

- Support groups can provide affordable training and professional development for their members which benefits the sector as a whole.

- Voluntary professional groups have traditionally provided opportunities for members to meet face to face. With the advent of virtual social networking such groups may have to adapt their role and actively promote the value of the activities which they provide. 
